\title{
Implantação da Gestão Participativa EM UnidADESDE CONSERVAÇÃO DO TIPO Parque na Cidade do Rio de Janeiro: DO CONFLITO À COLABORAÇÃO
}

\author{
Marcos Cohen \\ DattaradbemAdministraçãodeEmpresaspdaPUC-RJ , \\ MestradbemAdministraçãodeEmpresaspdaPUC-RJ e \\ GraduaçãoemEngenhaniadeProduçãopdaUFRJ. \\ Professor Assistenteda PUC- R \\ mohen@iagpueriabr.
}

Jorge Ferreira da Silva DautoradbenEngehharia deProdurgãopdaPUC-RY, MestradbemAdministraçãodeEmpresaspdaPUC-RJ e MestradoemElerrica eTdecomnicacespdoINPE shophop@iagpueriobr

\section{RESUMO}

O sórgãos governamentais gestores das unidades de conservação ambiental do tipo parque da cidade do Rio de Janeiro vêm enfrentando dificuldades na implementação das diretrizes do Sistema Nacional de Unidades de Conservação (SNUC) que objetivam a gestão participativa dessas unidades. Este artigo apresenta um recorte de uma pesquisa maior e foca na formação de conselhos consultivos como estratégia colaborativa utilizada pelos gestores dos parques. D e um total de oito parques estudados por meio de entrevistas com gestores e agentes sociais interessados, pesquisas documentais e observações diretas, são apresentados dois casos que retratam a formação de conselhos consultivos em parquese demonstram situações que vão do conflito entre os atores sociais e os responsáveis pela gestão até a plena colaboração durante este processo. O s resultados indicam que as iniciativas para estabelecer a gestão participativa por meio de um Conselho Consultivo no Parque Municipal do Bosque da Freguesia foram, em grande parte, ineficazes em razão da falta de normas específicas, de capacitação dos envolvidos e de recursos financeiros. Já no Parque Nacional da Tijuca, de gestão federal, a utilização de metodologia adequada, de caráter eminentemente democrático e participativo, aliado a um treinamento prévio de todos os envolvidos, resultou em sucesso e colaboração plena e serve de modelo para os demais parques.

Palavras-chave: Parques Naturais. Gestão Participativa. Conflito. Colaboração.

\section{ABSTRACT}

Govemmental agendes that manageenironmental protetedareas like minicipal parksin RiodeJamiroarefaingdiffialtiesin implementing the National Systemfor Conservation of Units (SNUC) guiddines, which aimfor theparticipativemanagement of these units This artidepresents part of a larger rearch projet and fouses on thefomation of adkisory coumils as a collaborative strateegy used bymmicipal park administration Basedoninterviens withmanages and stakdnddes secondary rearch anddireet dosevation, it is presented two cases that show theformation of adkisary counils in parks and demonstratesituations that goes from conflicts between soial actors and manages to full coppeation during theprocess Theresults indicate that theinitiatives to establish pertidpativemanagement with anadkisary cannil in Bosqueda Freguesia Municipal Park werelangdy inffetivedueto ladk of speificnoms, involved peepletrainingandfinamial resarces Honeverin Tijuca National Park, managedby a federal govemmental ageng, the use of an appropiatedemmoraticand participative mthooddog, allieel to previaus training of partsinvdved, resultedin a surcessful implementation andfull coperation, bing pinted asa modd of referene for ther parks

Key words: Natural Parks ParticipatoryManagenent. Conflic. Cdlaboration 


\section{INTROÇÃO}

Visando à preservação e/ ou uso sustentável de áreas diversas do território brasileiro com características naturais relevantes, foi promulgada no ano de 2000 a Lei 9985 que criou 0 Sistema Nacional de Unidades de Conservação Ambiental (SNUC) e regulamentou a gestão dos diferentes tipos de unidades de conservação ambiental no País. Entre elas, encontram-se as unidades de conservação (UC) integral, cujo objetivo básico é preservar a natureza, sendo admitido apenas o uso indireto dos seus recursos naturais. Os parques estudados nesta pesquisa se enquadram nesta categoria. A lei do SNUC identifica cinco grandes objetivos de uma unidade de conservação integral do tipo parque (BRA SIL, 2000, Capítulo III, Artigo 11으): "1-Preservar ecossistemas naturais de grande relevância ecológicae beleza cênica; 2-Possibilitar a realização de pesquisas científicas; 3-D esenvolver atividades de educação e interpretação ambiental; 4- Desenvolver atividades de recreação em contato com a natureza; 5-D esenvolver o turismo ecológico".

Tem-se constatado também crescente preocupação das médias e grandes cidades brasileiras com a conservação de suas áreas naturais por meio da criação de tipos diversos de unidades de conservação ambiental, sob responsabilidade dos governos federal, estadual ou municipal. Infelizmente, os resultados dessas ações nem sempre são os esperados, variando do fracasso total a soluções parciais e insatisfatónias. Isto descorre, em grande parte, da falta de recursos financeiros e humanos por parte dos governos, mas também, na opinião de muitos estudiosos do assunto, falta participação efetiva dos diversos segmentos da sociedade em tais empreendimentos (Horowitz, 2004; SILVA, BONILLA e OLIVEIRA, 2004).

Na cidade do Rio de Janeiro, há uma grande quantidade de unidades de conservação integral. Durante a pesquisa, havia dezessete parques naturais municipais, três estaduais e um nacional (SMAC, 2006). Cada um desses parques era administrado pelo órgão gestor responsável dentro da respectiva esfera de governo, o qual delega parte das atribuições a um funcionário do órgão que exerce o cargo de gestor do parque. Constata-se, porém, que uma boa parte dessas unidades de conservação oficialmente constituídas carece de infraestrutura e recursos financeiros, humanos e gerenciais suficientes para garantir sua autossustentabilidade. (PCRJ-SMAC, 2004; TCMRJ, 2005).

Foram também identificadas várias diretrizes básicas do SNUC que incorporam aideia da gestão participativa e colaboração, mencionadas a seguir (BRA SIL, 2000, Capítulo II, artigo 5o). A primeira delas estabelece que: "O SNUC será regido por diretrizes que assegurem a participação efetiva das populações locais na criação, implantação e gestão das unidades de conservação". Esta diretriz exprime de maneira implícita a responsabilidade dos órgãos gestores das unidades de conservação pela elaboração de estratégias que garantam a participação da sociedade nessa gestão, aqui denominada gestão participativa. Na verdade, o SNUC cria dois instrumentos da gestão das unidades de conservação do tipo parque que embutem este tipo de estratégia: o Conselho Consultivo e o Plano de Manejo elaborado com base em contribuições da sociedade. 0 Conselho Con- sultivo representa a mais poderosa ferramenta da gestão participativa, pois traz para dentro da gestão do parque os diversos atores sociais que podem influenciar positiva ou negativamente sobre esta unidade de conservação.

Este artigo apresenta um recorte de uma pesquisa maior, cujo objetivo era entender como as estratégias colaborativas utilizadas pelos órgãos gestores das unidades de conservação do tipo parque são implementadas e como afetam os resultados da gestão e o relacionamento com diferentes grupos de atores sociais envolvidos. Mais especificamente, 0 objetivo final deste artigo é apresentar dois casos de implantação e gestão de conselhos consultivos em parques do Rio de Janeiro que tiveram resultados opostos, analisando as causas desses resultados à luz da teoria sobre conflito e colaboração.

\section{REFERENCIAL TEÓ RICO}

\subsection{Conflitos Ambientais U rbanos e U nidades de Conser- vação}

Burton e Dukes (1990) definem os conflitos como enfrentamentos sociais causados por diferentes razões. Uma delas pode ser a disputa por questões ligadas ao meio ambiente. Neste caso, ela recebe o nome de conflito ambiental, sendo em geral resultante da ação de forças organizadas contra o Estado, o detentor dos direitos sobre o meio ambiente (BURGUESS, 1997). Bredariol (1997) complementa este conceito com a noção de tensões ambientais entre interesses privados e públicos (ou sociais), que não chegam a caracterizar um conflito, mas podem levar a ele, já que envolvem a disputa pela apropriação do meio ambiente comum em uma cidade. Já segundo D e Mio \& al. (2004), os conflitos ambientais são causados pela degradação ambiental, pela opção de desenvolvimento adotada e pela marginalização de setores da sociedade. Para ela, dentro do novo modelo de desenvolvimento sustentável, os interesses, que eram antagônicos, agora precisam ser integrados, a fim de se resolver o conflito.

Para Scandurra (1995), a cidade moderna tem papel fundamental e insubstituível como o ambiente do Homem, local de produção de riqueza, mas, ao mesmo tempo, um sistema dissipativo, que gera problemas ambientais e sociais. Para ele, as cidades industriais estão comprometendo de forma muito rápida as condições biofísicas que sustentam a vida no Planeta. Na mesma linha de Scandurra, Costa e Braga (2004) afirmam que a prática ambiental urbana no Brasil se tornou extremamente em virtude da grande heterogeneidade de nossa sociedade. Isto é facilmente constatado nas grandes cidades, onde os problemas oriundos da má distribuição de renda convivem com problemas causados pelo excesso de consumo das classes mais abastadas. As políticas públicas concebidas para tentar tratar desses problemas afetam os diferentes e complexos interesses dos vários grupos de atores sociais. Neste contexto, Costa e Braga (2004, p 199) definem o conflito ambiental urbano no Brasil: "Identificamos como principal foco do conflito de interesses em torno das políticas ambientais urbanas a tensão entre o uso público e privado dos recursos econômicos, sociais, cul- 
turais, bióticos e abióticos da cidade e de seu entorno, que são por principio, públicos".

Costa e Braga denunciam a lógica da valonização do capital no espaço urbano, que causaa exclusão de grande parte dapopulação do acesso à moradia e que gera, consequentemente, a ocupação ilegal das áreas ambientais protegidas, os espaços urbanos que acabaram sobrando para os pobres. Já segundo Acselrad (2004), tradicionalmente, o Estado tem dificuldade em enxergar a oposição como expressão as diferenças reais entre atores sociais a serem enfrentadas em arenas públicas democráticas.

$\mathrm{Na}$ cidade do Rio de Janeiro, as tensões e conflitos ambientais estão presentes em diversas regiões geográficas, entre esferas de governo, classes sociais e por atividades econômicas. Por exemplo, vários casos são relatados por pesquisadores (BREDARIO L, 1997) e órgãos públicos (TCM-RJ, 2005) envolvendo ameaças ao meio ambiente como resultado de expansão imo biliária desordenada da cidade em direção as suas últimas áreas verdes, sobretudo na região da Barra da Tijuca, promovida pela iniciativa privada. Em paralelo, o crescimento desgovernado das favelas em direção ao elevado dos morros ou ao longo de rios e canais, ameaça as unidades de conservação da cidade. Mais recentemente no Brasil, vários estudos são realizados no sentido de empregar metodologias de negociação na mediação de conflitos ambientais em meios urbanos, em um processo democrático (BREDARIO L, 2001). Segundo Bredariol (2001), há uma forte tendência em se adotar a gestão ambiental, as parcerias e a negociação como caminhos para resolução dos conflitos, tendo como base mecanismos tripartites, isto é, envolvendo o Estado, as empresas e a sociedade, caracterizando a adoção de estratégias colaborativas.

\subsection{E stratégias Colaborativas e sua A plicação ao C aso da Conservação Ambiental}

Faz-se necessário então definir o que é colaboração nas questões socioambientais e também identificar os diferentes tipos de colaboração que estão sendo praticados nessa área. G ray (1985) define colaboração como "aremiãodereursostanǵvese a fimde resdver um conjunto de problemes que nenhum deses pode resdver sozinho".

Sachs (1993) identificou três grupos de atores sociais responsáveis pelo desenvolvimento sustentável - o Estado, as empresas e o chamado terceiro setor, formado pelas 0 NG 's e movimentos comunitários. Como ele já havia notado naquela época, as formas de parceria e a distribuição de poder entre estes atores continuam sendo definidas, mas, com certeza, nenhum deles pode dar conta dessa tarefa isoladamente, quer pela complexidade, quer pela longa maturação de ações desta natureza. Falta ao Estado capacidade de entender as complexidades e necessidades locais, assim como falta às empresas o foco social e de longo prazo. Considerando estes grupos de atores sociais, pode-se afirmar, com base em Healey (1997), que cada vez mais as estratégias tradicionais de planejamento e desenvolvimento das sociedades, baseadas em critérios puramente econômicose sem a consulta e participação no processo de planejamento e na tomada de decisão, não são mais plausíveis. Há necessidade da adoção de um enfoque socioambiental, considerando os interesses das redes de atores sociais envolvidos.

Wondolleck e Yaffee (1997) refletem a respeito da dimensão colaborativa da gestão de ecossistemas e sobre o processo decisório na questão ambiental. Eles focam na solução não conflituosa das disputas envolvendo áreas ameaçadas pela atuação das empresas, buscando identificar os fatores que facilitam e os que impedem a colaboração. Especificamente em relação aos questionamentos sobre colaboração em questões ambientais, Wondolleck e Yaffee (1997) explicam que a colaboração pode levar a decisões mais eficientes e fáceis de plantar. Ao mesmo tempo, as comunidades e órgãos de governos que colaboram entre si adquirem habilidades que poderão servir em futuras situações, e um processo de aprendizado coletivo. Wondolleck e Yaffee (2000) alertam, porém, para barreiras institucionais e estruturais presentes nas complexas situações de projetos ou conflitos ambientais. As principais barreiras por eles identificadas são: falta de oportunidades e incentivos; objetivos antagônicos das partes; inflexibilidade de políticas e procedimentos das partes envolvidas, recursos limitados, falta de confiança mútua enormas e cultura organizacionais. Wondolleck eYaffee (2000) propõem algumas ações para superar essas barreiras, tais como: eliminar as percepções erradas entre parceiros e incentivar o entendimento mútuo por meio de contatos frequentes, inclusive informais; focar nos indivíduos e não as organizações, pois as parcerias são essencialmente feitas de pessoas, e incentivar a confiança e o respeito mútuos.

Nesse contexto, a expressão "estratégias colaborativas" incorpora diversos tipos de arranjos colaborativos, temporários ou não, com muitos ou poucos participantes, oficiais ou informais, incluindo alguns tradicionais como alianças estratégicas ou redes, como, por exemplo, parcerias simples - focadas em um ou dois temas, envolvendo um pequeno número de parceiros e possuindo uns poucos objetivos específicos; parcerias múltiplas - envolvendo um grande número de parceiros, em geral em torno de projetos ambientais mais complexos; e coordenação entre agências (órgãos de governo, que são ações integradas entre órgãos do mesmo governo ou de governos diferentes para atingir objetivos comuns em questões ambientais (WO ND O LLECK e YAFFE E, 2000). Nesta pesquisa o foco de estudo é a gestão participativa de unidades de conservação, que contempla a participação da comunidade do entorno de uma unidade de conservação por meio de um Conselho Consultivo (BRASIL, 2000).

\subsection{E xperiências Brasileiras com Gestão Participativa de Unidades de Conservação}

Na tentativa de entender como ocorre a colaboração em meio ambiente no Brasil, pesquisaram-se diversos casos recentes, inclusive em unidades de conservação, brevemente relatados aqui, dando-se ênfase aos casos em que foram utilizados instrumentos da gestão do tipo Conselho G estor ou Consultivo. A importância desse tipo de ferramenta é enfatizada por Gohn (2001). Com base em experiências de conselhos gestores 
em diversas áreas da gestão municipal, G ohn afirma que a experiência participativa pode resultar em cidadãos ativos e politizados, com visão crítica da realidade e compreensão sobre as causas e origens dos problemas que os envolvem, ainda que haja sempre o risco de esses cidadãos ativos terem atuações individualizadas e personalistas, muito distantes de qualquer sentido público. Já Roper (2000) informa que a gestão participativa em unidades de conservação ainda é problemática na prática, sobretudo em áreas de proteção ambiental, que contemplam o conceito de desenvolvimento sustentável. Nestas áreas, os interesses são mais conflitantes, dado que é permitida a atividade econômica em certas zonas da unidade.

Horowitz e Bursztyn (2004), por sua vez, descrevem as ações de planejamento e manejo das unidades de conservação federais do grupo de proteção integral e analisam suaimplantação no Parque Nacional de Brasília. Em função das dificuldades encontradas durante esse processo, elas identificaram diversos fatores, que, quando combinados, contribuem decisivamente para o fracasso da iniciativa. D estacam-se deles: a frágil organização e estrutura das instituições responsáveis pela gestão do parque; falta de interação intra e interinstitucional; a descontinuidade administrativa; a falta de pessoal capacitado e a falta de verbas suficientes. Nota-se que a maioria dos fatores tem relação com problemas estruturais e de financiamento. Entre as diversas propostas, incluem a capacitação dos recursos humanos do órgão responsável no sentido de se integrar às necessidades da sociedade.

Por outro lado, O liva e Costa Neto (2000) compartilham uma experiência interessante de planejamento e gestão participativa em dez unidades de conservação de proteção integral do Estado de São Paulo, iniciada em 1997, e que desembocou na criação de comitês de apoio à gestão. Segundo eles, 0 processo foi fruto de um esforço institucional das equipes envolvidas no sentido de criar canais de comunicação com as diversas comunidades. Por volta de 2000, no entanto, em função da existência de uma série de conflitos envolvendo a ocupação humana do entorno e seu reflexo no manejo das unidades e considerando a inexistência de uma política pública do Poder Executivo do Estado para resolver os impasses surgidos, os conflitos se agravaram e causaram a paralisação dos comitês. Ainda assim, os coordenadores continuaram atuando no sentido de mediar os conflitos. A lição que fica é que as ações participativas descentralizadas nas unidades de conservação devem ser acompanhadas de políticas e respostas rápidas e concretas por parte do governo, a fim de manter a credibilidade do processo junto aos agentes sociais envolvidos.

Mais recentemente, Teixeira \&al. (2004) relatam a criação do Conselho Consultivo da Área de Proteção Ambiental - APA em João Leite, G oiás, descrevendo a metodologia abordada e as etapas. Para eles, a grande importância do Conselho foi permitir que a comunidade participasse da gestão da APA , o que acabou por criar em seus membros o senso de corresponsabilidade pela área. Segundo Teixeira eal. (2004), as ações procuraram envolver a comunidade permanentemente e o Conselho criado caminhou em direção a uma gestão participativa. A quantidade de participantes no Conselho impressiona: trinta e sete entidades, sendo dez órgãos públicos estaduais, sete entidades de classe, seis ONGs, um comitê de bacia hidrográfica, cinco entidades de ensino e oito órgãos públicos municipais, de forma praticamente paritária. Eles concluem aprovando a experiência e indicando ser este o caminho a ser seguido para as demais unidades de conservação de Goiás, principalmente por meio da inclusão das organizações mais relevantes da região no Conselho.

0 que é exatamente, porém. um Conselho Consultivo? O SNUC trata do Conselho Consultivo das unidades de conservação do grupo integral (BRASIL, 2000, artigo 293 e estabelece que cada unidade de conservação integral do tipo parque deverá dispor de um Conselho Consultivo a ser presidido pelo órgão responsável por sua administração e constituído de representantes de órgãos públicos e de organizações da sociedade civil. Já o decreto 4340 de 2002 (BRA SIL, 2002, capítulo V) regulamenta o Conselho Consultivo, podendo-se destacar a representação dos órgãos ambientais dos três níveis da Federação e órgãos de áreas afins, tais como pesquisa científica, educação etc; a representação da sociedade civil por meio de organizações não governamentais ambientalistas, da população residente e do entorno etc. A representação dos órgãos públicos e da sociedade civil nos conselhos deveria ser, sempre que possível, paritária.

É importante ressaltar a participação da sociedade civil no Conselho Consultivo com representação preferivelmente paritária à representação do Poder Público. Esta é uma inovação importante na legislação ambiental. Jáno decreto 4340, de 2002, são estabelecidas as competências do Conselho, de caráter não deliberativo, destacando-se entre elas: 0 acompanhamento da elaboração do Plano de Manejo da UC, a avaliação do orçamento e do relatório financeiro anual, opinião sobre formação de parcerias com O SCIPs, a manifestação sobre atividades potencialmente causadora de impacto na UC ou seu entorno, e a proposição das diretrizes e ações para desenvolver melhores relações com a população do entorno ou do interior da UC (Brasil, 2002). Percebe-se uma ampla variedade de atribuições, o que indica a clara necessidade de capacitar tanto os gestores quanto os membros do Conselho sobre suas responsabilidades, principalmente sobre instrumentos de gestapo, como plano de manejo, já que está prevista (ainda que não seja obrigatória para parques) a participação consultiva dos membros do conselho na elaboração deste plano.

\section{METODOLOGIA}

Com base em Creswell (2003) e Remenyi et al. (1998), procurou-se estabelecer a estratégia de pesquisa de acordo com os objetivos estabelecidos, optando-se por uma pesquisa exploratória, pois buscou-se obter um conhecimento inicial sobre um campo de estudo relativamente pouco estudado, no Brasil, o das estratégias colaborativas aplicadas à gestão de unidades de conservação. Isto levou à opção por uma abordagem eminentemente qualitativa (CRESWELL, 2003) e pela adoção da estraté gia de múltiplos estudos de caso em razão de sua vantagem de responder adequadamente às perguntas "como" e "por quê" 
sobre o fenômeno estudado (Y IN, 1994). Usando critérios propostos porY in (1994), buscou-se garantir a validade dos conceitos estudados pelo uso de múltiplas fontes de evidência (triangulação entre entrevistas de partes diferentes envolvidas, coleta de documentos oficiais dos governos e dos responsáveis pelos parques e de documentos gerados por outras entidades, consulta a páginas da Internet das partes envolvidas) e revisão de conclusões por alguns entrevistados-chave. A validade externa (capacidade de generalização da pesquisa) foi garantida, ao menos parcialmente, pela abordagem de múltiplos estudos de caso. 0 universo da pesquisa constou dos vinte e um parques existentes na cidade do Rio de Janeiro na ocasião da pesquisa. Foram selecionados oito dels, representando as três esferas de governo, sendo que este artigo contempla estudos de caso referentes a apenas dois deles, pois são os mais relevantes em termos de formação do Conselho Consultivo e mostram situações extremas: o Parque Nacional da Tijuca (federal) e o Parque Natural Municipal Bosque da Freguesia.

A coleta de dados referente a estes dois parques incluiu 44 (quarenta e quatro) entrevistas com os responsáveis dos órgãos gestores centrais, com os gestores dos parques e com representantes de vários grupos de agentes sociais interessados na gestão dos parques (O NGs, empresas, associações de moradores e classistas, instituições de ensino e pesquisa, associações políticas, entre outras). As entrevistas semiestruturadas foram realizadas com base em listas de questões abertas preelaboradas, tendo sido os gestores dos parques entrevistados mais de uma vez em diferentes momentos. A fase de coleta de dados durou de novembro de 2005 a fevereiro de 2007, mas buscou levantar dados desde a data da criação da Lei do SNUC (julho de 2000). 0 tratamento dos dados foi eminentemente qualitativo, usando-se um softwarede Análise de Conteúdo (A tlas versão 4.2) como suporteà análise das entrevistas transcritas. D urante 2008, após o encerramento da pesquisa, foram contatados gestores dos dois parques aqui analisados e feita uma revisão de notícias, buscando atualizar o statusdos conselhos consultivos.

\section{RE SULTAD OSDA PESQUISA}

\subsection{Caso do Parque $\mathrm{N}$ atural M unicipal do Bosque da Freguesia: Conflito}

O Parque Natural Municipal (PNM) Bosque da Freguesia localiza-se no bairro da Freguesia, na região de Jacarepaguá. A área do bosque é de 31 hectares, sendo quase totalmente antropizada e constituída de muitas espécies vegetais exóticas (PCMRJ, 1998). No início dos anos 1990, a área foi vendida a uma concessionária de veículos que lá pretendia construir uma loja, no entanto, associações de moradores locais e O NGs ambientais iniciaram um movimento, com passeatas e referendo popular, em defesa da conservação do bosque, já usado pelos moradores para seu lazer, na tentativa de ali criar um parque público. Assim, como resultado desse movimento da sociedade e da aliança de vários setores, o bosque foi tombado pela Câmara de Vereadores em 1992 com o objetivo de proteção de suas áreas verdes. Após mais de dez anos de luta da comunidade local, o bosque foi transformado no PNM Bosque da
Freguesia, pelo decreto 22.662, de 19 de fevereiro de 2003, passando à tutela da SMAC.

Segundo a gestora do PNM Bosque da Freguesia, desde 0 início de sua atuação no parque, ela buscou formar alianças com os representantes das associações, que, segundo suas palavras, efetivamente comandavam o parque quando este ainda estava sob a tutela da Fundação Parques e Jardins. 0 caminho encontrado por ela foi propor a criação de um Conselho Consultivo, como previsto na lei do SNUC. De acordo com a Resolução SMAC n-334 30, de outubro de 2003, foi instituído o Conselho Consultivo do PNM Bosque da Freguesia, composto por seis membros do Poder Público e seis da sociedade civil, legalmente constituídas há pelo menos um ano, e que eram: um representante de entidade comercial local (Rio Shopping; um representante de O NG ambiental local (GRUDE); três representantes de associações de moradores da população residente no local, no caso AABF (Associação dos Amigos do Bosque da Freguesia), AMAF (Associação de Moradores e Amigos da Freguesia) e FAM Rio (Federação das Associações de Moradores do Rio de Janeiro); e um representante de universidade ou de instituição científica, privada, de pesquisa e proteção do meio ambiente, no caso a Universidade Estácio de Sá.

É fundamental entender as motivações dos atores sociais para participarem do Conselho Consultivo do PNM Bosque da Freguesia e como avaliam seu funcionamento durante estes mais de três anos. 0 presidente daAssociação de Moradores da Freguesia (AMAF) reclama para sua associação a ideia de criação do Conselho, enxergando nele a possibilidade de ter um canal oficial de comunicação com a Prefeitura, por meio do qual seria possível colocar suas demandas sobre o parque. 0 presidente daAMAF não esconde, no entanto, certo desapontamento com os resultados obtidos pelo Conselho Consultivo, sobretudo pela falta de verbas para aplicação no parque:

É como eu estou dizendo, o conselho vem pressionando e vem provocando tudo que é necessário ser feito aqui dentro, mas quando chega lá em cima, as verbas acabaram, as verbas foram desviadas, as verbas tomaram rumo diferente.

Já o presidente da Associação dos Amigos do Bosque da Freguesia (AABF) relata sua participação na concepção do Conselho. Segundo ele, a ideiajá existia quando a gestora chegou ao parque e, por meio de discussões com a AABF, a ideia foi aprofundada e um estatuto provisório elaborado. Ele compartilha da mesma noção de que, por meio do Conselho Consultivo, é possível maior aproximação da Prefeitura, que se trata de um fórum para discussão dos problemas do parque, mas questiona a paridade do Conselho (seis membros do governo e seis da sociedade civil organizada), pois entende que a população deveria ter mais peso na decisão. Q uanto à efetividade do Conselho, o presidente da $\mathrm{AABF}$ acha que ela élimitada, em razão da pouca força da gestora para levar as questões para a cima na hierarquia da Prefeitura. Ele entende que as associações que participam do Conselho podem e devem usar outros meios paralelos para pressionar a prefeitura a atender às deliberações do Conselho. Ele também entende que as reuniões deveriam ser 
realizadas com uma frequência maior do que vem acontecendo, em média, a cada três meses. Já para o diretor do GRUDE , a existência do Conselho trouxe alguns ganhos para o parque, como, por exemplo, o aumento do efetivo de guardas dentro do parque e a contratação da vigilância patrimonial particular para as duas entradas, liberando os guardas municipais que ficavam na entrada para poderem circular no Bosque.

Durante a pesquisa, o pesquisador participou de duas reuniões do Conselho Consultivo do parque. A primeira delas foi o estopim de uma crise de relacionamento entre a gestora e os membros da $\mathrm{AMAF}$ e da $\mathrm{AABF}$, que será aqui relatada. $\mathrm{Na}$ segunda reunião, a crise se agravou. O s fatos serão brevemente descritos e analisados a seguir:

\section{1- Descriçada 7ậraniãodbConsdho, en10 deabril de2006 einía da cise}

Esta reunião teve como objetivo principal propor o fechamento dos PNM Bosque da Freguesia às segundas- feiras, como previsto na Lei do SNUC. A gestora apresentou o gestor do Parque Natural Municipal Chico Mendes, que fez breve palestra sobre a necessidade de se fechar o PNM Bosque da Freguesia, como acontecia em todas as demais unidades de conservação da Prefeitura, conforme decreto municipal. Segundo ele, o fechamento do parque uma vez por semana permitiria que se realizasse o manejo de espécies animais e vegetais, que se realizasse a manutenção de trilhas e que os animais pudessem descansar e realizar algumas atividades sem a presença de pessoas por perto. Além disso, permitira a realização de pesquisas científicas sem o risco de interferência de pessoas estranhas. A gestora do PNM Bosque da Freguesia reforçou o discurso de gestor do Chico Mendes, falando do risco de se podar árvores com a presença de visitantes nas trilhas.

O presidente daAMAF pediu a palavra e começou a reclamar de falta de sinalização no parque e relembrou que o prédio da sede só foi construído por pressão da AMAF. O presidente da AABF tomou a palavra e reclamou da Secretaria de Meio Ambiente e da Prefeitura e sugeriu que a decisão de se fecharo parque fosse mais amplamente discutida com a comunidade antes de ser tomada. Sua posição era quea AABF estava ali não para decidir, mas para tomar conhecimento da proposta a fim de elaborar um documento que a explicasse à população a fim de permitir que as pessoas dessem opinião a respeito.

Como o clima de discussão ficasse mais exaltado, inclusive com elevação do tom de voz e troca de palavras mais ásperas entre a gestora e os representantes da AMAF eAABF, percebeuse que as associações de moradores não eram favoráveis ao fechamento do parque às segundas-feiras. A reunião foi encerrada mais cedo, por não haver diálogo entre as partes. Notou-se também que três diferentes tipos de enfoques se chocaram durante a reunião. 0 primeiro foi o "enfoque técnico" dos dois gestores, que tentaram justificar o fechamento do parque, já decidido aprion pela SMAC, com termos e critérios técnicos, muitos dos quais pouco compreensíveis para alguns dos presentes. $O$ segundo foi o "enfoque emocional" do presidente da AMAF, que frequenta o parque todos os dias há muitos anos e simplesmente não aceita a perda desse direito. 0 terceiro foi " 0 enfoque político" do presidente daAABF, que até poderia estar disposto a aceitar 0 argumento técnico, desde que este fosse discutido mais abertamente e, possivelmente, num fórum maior, que envolvesse a possibilidade de opinião por parte dos frequentadores do parque.

Com base nas observações, entende-se que faltou à gestora adotar uma estratégia mais democrática para resolver 0 problema, pois ela já trouxe uma decisão tomada para ser comunicada imposta a um fórum democrático por excelência, mesmo não tendo o mesmo caráter deliberativo. Também faltou a ela um pouco mais de flexibilidade para ouvir as críticas e abrir a proposta para a discussão, a fim de amadurecer mais a ideia. Na segunda entrevista com a gestora, em 21 de julho de 2006, ela alegou que o tema já vinha sendo abordado há bastante tempo (na verdade, desde outubro de 2005, segundo a própria $A A B F)$ em reuniões informais, mas que as associações estavam refratárias à idéia. Ela reconheceu, no entanto, que perdeu a paciência durante a reunião, pois já estava cansada das mesmas reclamações em tom agressivo feitas por alguns dos presentes em várias reuniões anteriores.

\section{2- EvduçãodaCniseapósa 7ª̣naniãodoConsdha}

No dia21 de maio, a gestorainformou aos frequentadores do parque por meio de um folheto de que a partir de 12 de junho de 2006 o Parque Natural Municipal da Freguesia não seria mais aberto ao público às segundas-feiras, ficando aquele dia reservados para sua manutenção e realização de pesquisa científica. Esta ação provocou imediata reação e mobilização da AMAF e da AABF. Houve troca de e-mails, entre a gestora e a AABF, com cópia para os membros dos conselhos e outros atores sociais que faziam parte da rede virtual de comunicação dos dois grupos. Nesta troca de e-mails aparecem tentativas da AABF de marcar reuniões com a gestora no início de junho e reclamações da gestora quanto ao tratamento dado a ela pela AABF e AMAF.

Em 2 de junho, a AABF enviou por e-mail uma chamada os seus associados, convocando-os a participarem de uma reunião em 3 de junho, que discutiria a decisão "unilateral e precipitada" da administração do parque.de fechá-lo às segundas-feiras. Como resultado dessa reunião, foi elaborado e entregueà gestora um documento pela AMAF E AABF, contrapondo os motivos e argumentos dessas associações àqueles que teriam sido utilizados pela administração do parque. Note-se que alguns dos argumentos citados no documento (por exemplo, a de que o homem "maltrata e alimenta os animais, mudando seus hábitos alimentares e prejudicando a saúde") não foram utilizados pela gestora no folheto distribuído ao público. A análise de alguns dos argumentos usados pelas associações mostra que prevalece neles a lógica antropocêntrica, ou seja, a de que os interesses do homem são mais importantes do que os da natureza, deixando vislumbrar a falta de maior compreensão dos mecanismos que regem a relação homem-natureza e dos objetivos de uma unidade de conservação. Isto talvez seja fruto da falta de capacitação específica dada aos membros do Conselho Consultivo, durante 
sua formação. Também foi dito antes que um diálogo mais frequente e aberto entre as parte talvez pudesse ter evitado quea crise fosse gerada ou evoluísse de forma descontrolada.

Na segunda-feira, 12 de junho, o parque não abriu. Entre 13 e 17 de junho as duas associações tentaram, sem sucesso, agendar uma reunião com a gestora. Entre 20 e 26 de junho, as duas associações juntaram-se à FAMRio e lançaram uma campanha com panfletagem dentro do parque e no seu entorno contra o fechamento do parque às segundas-feiras e realizaram uma consulta junto aos frequentadores por meio de um questionário. Segundo o presidente da AABF, na consulta foi apurado que $61 \%$ dos respondentes (não foi informado o total) não queriam o Bosque fechado Às segundas-feiras, e só 7\% aceitavam 0 bosque fechado nesses dias. 0 utros $21 \%$ aceitavam 0 fechamento do parque a partir das doze horas nas segundasfeiras, enquanto que os restantes $11 \%$ entendiam que o parque deveria fechar somente uma segunda-feira por mês. 0 resultado foi então divulgado e marcado um ato público. No dia 29 de junho foi realizada uma reunião (a 8ª) extraordinária do Conselho Consultivo do parque para que, segundo a gestora (BF08), se pudesse reiterar a justificativa de seu fechamento às segundas feiras. Esta reunião foi interrompida em virtude das discussões entre as partes presentes. $O$ presidente da $\mathrm{AABF}$ informou que durante a citada reunião com a Secretária do Meio Ambiente, as associações propuseram uma solução intermediária, na qual o parque fecharia às segundas-feiras após as doze horas durante um ano, período no qual se tentaria convencer os frequentadores da necessidade do fechamento integral às segundas-feiras.

\section{3- Descriçãoda 9âremiãodbConselho, em17 dejulhode2006.}

Nessa reunião, a gestora do parque distribuiu entre os presentes uma carta por ela elaborada, na qual relatava os episódios da reunião extraordinária já descritos, sob a sua óptica, e informava que, em virtude da reunião ocorrida entre a Secretária de Meio Ambiente e as associações locais da Freguesia, a SMAC havia deliberado a proposta de voltar a abrir o parque às segundas-feiras a partir do dia 24 de julho, no horário de sete às dez horas, para que a gestora e os parceiros locais pudessem explicar aos frequentadores sobre a necessidade de fechamento do parque em tempo integral uma vez por semana, o que voltaria a acontecer, em caráter definitivo, em 21 de agosto. Apesar de essa reunião ter transcorrido quase todo o tempo sem maiores altercações entre as partes presentes, tendo a gestora adotado um tom mais conciliador, o teor da carta foi mal recebido pelas associações, que se sentiram injustiçadas ao serem acusadas de desrespeitar funcionários da SMAC e não viam na proposta nenhum ganho substancial. A reunião terminou de novo em discussão entre o presidente daAMAF e a gestora, sem se chegar a qualquer resolução sobre as propostas. Mais uma vez, ficou nítido que a reunião foi pouco democrática, pois, na prática, a SMAC fazia muito poucas concessões às associações ao contrapropor 0 adiamento do fechamento definitivo por apenas um mês, quando a proposta original era de um ano. A estratégia de produzir uma carta oficial poderia ter funcionado caso seu teor tivesse sido neutro, em vez de culpar as associações pela confusão ocorrida na reunião extraordinária do Conselho. Este ponto em particular foi decisivo para que as associações não se dispusessem a discutir a contraproposta. Em consequência dessa crise, a relação entre a gestora e as duas principais associações de moradores locais ficou bastante abalada, tendo as associações, inclusive, solicitado à Secretaria do Meio Ambiente que exonerasse a gestora. 0 pedido não apenas não foi atendido, como a Secretaria acabou por acatar o parecer técnico da G erência de Unidades de Conservação (GUC) e optou pela manutenção da decisão inicial de fechar o parque integralmente às segundas-feiras, medida essa que vigora até hoje.

Segundo informações da gestora (fornecidas após o encerramento da coleta de dados), não houve mais reuniões do Conselho Consultivo do parque desde então. A última consequência da crise do Conselho Consultivo do PNM Bosque da Freguesia foi a decisão da Secretaria de Meio Ambiente de suspender todos os processos de criação de conselhos consultivos nos parques municipais e de criar um grupo de trabalho para elaborar normas para a criação e funcionamento de conselhos consultivos em unidades de proteção integral e de uso sustentável no Município. Esta tarefa estava sendo coordenada pela nova gerente da G UC e tinha previsão de conclusão para final de abril de 2007, mas, em meados de 2008, ainda estava "sendo finalizada". A gestora do PNM Bosque da Freguesia acabou sendo retirada do cargo e transferida para outro parque em 2008, em função do desgaste com os membros do Conselho.Quando perguntada sobre as lições que poderiam ser tiradas da crise, a gestora do PNM Bosque da Freguesia enfatizou que, apesar dos erros cometidos, a experiência do conselho consultivo foi excelente, porém, ela entende que o Conselho não pode ser implantado e gerido somente à base de um processo de tentativa e erro. Nesse sentido, ela entende que a formação dos Conselhos Consultivos dos parques deveria ser fruto de um estudo apurado e de preparação dos gestores e agentes sociais participantes. Ela imagina que este processo possa levar de seis meses a um ano e envolveria um grupo de trabalho para ajudar os gestores. Ainda segundo a gestora, seria necessário 0 acompanhamento permanente do andamento do Conselho, por meio de metas e indicadores de desempenho.

Analisando-se a crise relatada aqui, pode-se perguntar por que ela ocorreu, já que com certeza as partes envolvidas tinham como objetivo, em última instância, a boa gestão do parque e estavam altamente motivadas em relação a tal objetivo. A explicação pode envolver diferentes aspectos do problema. Um delesé a heterogeneidade do grupo de agentes sociais que formava o Conselho, cada qual com visõ es muito próprias sobre o parque e seus próprios códigos de valor que levam a diferentes interpretações do que é bom ou não para eles. Assim, enquanto a AMAF é representada por um morador que, pelo tempo que frequenta o parque o enxerga quase como a extensão de sua casa, a AABF parece ser uma associação de cunho ideológico, que se proclama "mobilizadora e de massa" e que visava a expandir a discussão do fechamento do parque a toda a comunidade do entorno. Acabam adotando os enfoques distintos já citados antes. Além disso, o histórico de participação decisiva

CONTEXTUS Revista Contemporânea de Economia e Gestão. Vol.7 - № 1 - jan/ jun/ 2009. (81-92). 
dos dois grupos na criação do parque talvez tenha criado em seus membros a sensação de serem partes inseparáveis de qualquer processo decisório que aconteça, principalmente se a decisão afeta a visitação do público aos parques. Este tipo de posicionamento deveria ter sido levado em consideração pela SMAC e pela gestora ao elaborarem a estratégia para fechar o parque às segundas. Um processo mais demorado de negociação com estas associações antes de implantar qualquer medida seria mais indicado para evitar o conflito. As personalidades dos indivíduos que representavam estes grupos ea da gestora, bem como o desgaste representado por mais de dois anos de discussões, também contribuíram para exaltar os ânimos.

É evidente também que, durante este processo, faltaram alguns instrumentos básicos de criação e gestão do Conselho Consultivo, quais sejam:

1 - normas e procedimentos para criação de conselhos consultivos, incluindo aí a identificação de todos os possíveis participantes e processo democrático de escolha dos membros;

2 - metodologia de gestão de conselhos consultivos;

3 - capacitação do gestor dos parques para criar e presidir conselhos consultivo;

4- capacitação dos gestores para planejar e conduzir reuniões de forma organizada e democrática;

5 - capacitação mais efetiva dos membros do conselho sobre unidades de uonservação (SNUC) e sobre o funcionamento do conselho consultivo; e

6 - uma equipe multidisciplinar de apoio aos Conselhos Consultivos na SMAC, que acompanhe, oriente e avalie o funcionamento dos conselhos consultivos, com base em metas e indicadores.

\subsection{Caso do Parque $\mathrm{N}$ acional da Tijuca - Colaboração}

O Parque Nacional daTijuca (PARNA daTijuca) é a mais famosa e visitada das unidades de conservação do tipo parque no Rio de Janeiro, fundamentalmente por estarem nele localizadas algumas das atrações naturais mais famosas da cidade e aquela que, sem dúvida, é o símbolo do Rio: a estátua do Cristo Redentor, no topo do pico do Corcovado. O Parque Nacional daTijucafoi criado pelo D ecreto Federal no 50.923 , de 6 de julho de 1961, e teve seu nome e limites alterados pelo D ecreto Federal $\mathrm{n}$-60.183, de 8 de fevereiro de 1967.0 parque tem atualmente 3.953 hectares, sendo, portanto, o segundo maior parque da cidade. Em 1991, foi declarado Reserva da Biosfera pela UNESCO. O ecossistema presente no parque é a mata atlântica de altitude, caracterizando-se a floresta por ser quase toda ela secundária, em adiantado estado de regeneração (PCRJ, 1998). O parque localiza-se no Maciço da Tijuca, sendo cercado porárea urbana em todos seu perímetro, o que aumenta consideravelmente a pressão antrópica sobre ele e cria uma série de ameaças a sua conservação. Ainda assim, o parque desempenha papel fundamental na vida da cidade, pois, além de servir como fonte delazer e geração de renda por meio do turismo, mantém diversas fontes de água que abastecem a população de seu entorno, previne a erosão das encostas, enchentes e desabamentos e re- duz a poluição atmosférica na cidade, tornando seu clima mais ameno. 0 caso do PARNA da Tijuca deve ser entendido em dois contextos temporais: 0 primeiro, a partir da data de $18 \mathrm{de}$ julho de 2000, quando for estabelecido SNUC, até o início do Programa "Água em Unidade de Conservação" em 2005 e 0 segundo após o início desse programa até o final de 2006, quando se encerrou a coleta de dados da pesquisa.

O Programa "Água em Unidades de Conservação" surgiu como resultado de uma parceria entre a gestão do PARNA da Tijuca e a O NG ambiental Instituto Terra Azul, financiado pelo Programa Petrobras Ambiental. O s projetos são selecionados publicamente e têm prazo de dois anos para serem implementados. O Instituto Terra Azul é uma ONG criada em 1997, com sede na Barra da Tijuca, Rio de Janeiro, que trabalha a partir de três eixos temáticos: meio ambiente, cultura e iniciação profissional, operacionalizados por meio de três centros de formação e capacitação. 0 Instituto Terra Azul desenvolve desde a sua criação programas e metodologias de suporte às ações públicas de governos e da sociedade civil voltadas para o desenvolvimento sustentável. Em 2004, quando houve a abertura do concurso Petrobras Ambiental, agestão do PARNA daTijuca convidou o Instituto Terra Azul para trocar ideias sobre a possibilidade de ações conjuntas em torno de um amplo projeto que envolvesse 0 monitoramento de água dentro do parque, ações de reflorestamento e recuperação da flora local e a reformulação do Conselho Consultivo. 0 projeto, denominado "Água em Unidade de Conservação", foi detalhado em conjunto e foi um dos escolhidos pela Petrobras Ambiental em 2004, iniciado em 2005 e concluído no final de 2006. Este projeto foi tão bem-sucedido que foi renovado e tinha novas etapas em execução ao final de 2008. 0 projeto objetivou principalmente reforçar as ações de proteção dos mananciais do Maciço da Tijuca, promovendo ações de reflorestamento, de Educação Ambiental e de monitoramento da qualidade de suas águas (PETRO BRÁS, 2006). 0 enfoque utilizado foi o de uma reflexão sistêmica e integrada que visou colaborar com a implantação da gestão participativa no PARNA da Tijuca.

As principais linhas de ação do projeto foram: 1.Monitoramento e qualidade da água; 2- Proteção, manejo e recuperação da flora e do solo; 3- Educação Ambiental para gestão comunidade / escola; 4- Planejamento e gestão paraa sustentabilidade econômica e 5- Conselho Consultivo. (PRO GRAMA PETROBRÁSAMBIE NTAL, 2005). Será analisada neste artigo somente a linha de ação 5, que se enquadra na diretriz do SNUC de "assegurar a participação efetiva das populações locais na criação, implantação e gestão das unidades de conservação (BRA SIL, 2000, Artigo 5o. - Parágrafo III).

\section{1'-fase-ConsedhoConsultivofomadosemparticipargãoda sociedade}

O PARNA da Tijuca teve seu primeiro Conselho Consultivo criado em 06 de agosto de 2002 por meio da Portaria ${ }^{\circ} .98$ do IBAMA. Segundo a gestora do parque, a formação desse Conselho foi solicitada às pressas pelo IBAMA. Assim, a gestora teve pouquíssimo tempo para nomear os membros do Conselho, o que evidentemente foi feito de forma não participativa e 
sem qualquer metodologia. 0 Conselho resultante não era sequer paritário, como informou o presidente da Associação dos Amigos do Parque Nacional da Tijuca - AAPNT:

Era um conselho muito...,Não era paritário, eram muito mais instituições voltadas, vamos dizer assim, de autarquias, quer dizer, mais órgãos do governo do que de sociedade civil. Sociedade Civil tinha a Fundação Roberto Marinho, tinha o IBASE e tínhamos nós, eu acho que só. $O$ resto todo era Corpo de Bombeiro, Polícia Militar, Polícia Civil, Polícia Federal, FEEMA, SERLA, CEDAE, quer dizer, usuários do parque, Light.

Como resultado desse processo hierarquizado, não participativo e distante da realidade social que cercava o PARNA da Tijuca, o Conselho pouco evoluiu desde sua criação, com poucas reuniões e sem grande contribuição à gestão do parque.

\section{2a . Fase- Consdho formado coma participeção da scielade, dentro} Prgito “ÁguasemUnidades deConservação".

Dentro da linha de ação desse projeto, denominada "Educação - Conselho Consultivo" , o diretor do Instituto Terra Azul relatou a formação de uma parceria com o Instituto Brasileiro de Análises Sociais e E conômicas (IBASE), O NG fundada em 1981, pelo falecido sociólogo Herbert de Souza, o Betinho. Segundo a definição em sua página na Internet, "a missão do IBASE é a construção da democracia, combatendo desigualdades e estimulando a participação cidadã" (IBASE, 2006). Com base nesta missão, o IBASE utilizou, em acordo com Coordenação G eral de Educação Ambiental do IBAMA, uma metodologia participativa que tinha como objetivos facilitar a comunicação agentes os atores sociais e viabilizar a construção coletiva de uma arena de debate enegociação dos diversos interesses em jogo. A meta final era alcançar uma aprendizagem coletiva que fortalecesse a gestão participativa do PARNA da Tijuca, conforme previsto no SNUC (IBASE 2005). A primeira fase da recomposição do novo Conselho Consultivo do PARNA da Tijuca foi a realização do diagnóstico socioambiental do parque e seu entorno, com os objetivos principais de identificar potencialidades, problemas e conflitos entre os diferentes grupos de agentes sociais envolvidos e identificar os grupos de interesse com vistas à recomposição do Conselho Consultivo, aí incluídos potenciais parceiros e grupos mais vulneráveis, como favelados. Para isso, foi utilizada a metodologia participativa de grupos focais (IBASE , 2005).

O Diretor do Instituto Terra Azul relatou o processo de diagnóstico socioambiental:

A estratégia foi montar grupos focais. Essa é uma parceria com o IBASE. O IBASE ajudou na formação e reestruturação do conselho consultivo. E a proposta aí apresentada por eles era de que identificássemos ...dentro da sociedade civil quais seriam os segmentos representativos, igrejas, O NGs, instituições que desenvolvem projetos com o parque; também da iniciativa privada. Aí mapearmos tudo isso e iniciarmos reuniões com cada grupo desses. Então foi feito um mapeamento e várias entidades foram convidadas no ano passado, ...que a gente chamou de encontros de grupos focais. Foi feita ali uma explanação para eles sobre o projeto, a proposta da formação do conselho, o que era o conselho consultivo, a importância e a avaliação de como eles entendiam e se viam numa relação com o Parque Nacional da Tijuca, como é que eles gostariam também de se ver.

A escolha do método participativo de grupos focais para obter os dados a partir dos atores sociais mobilizados se deveu a sua capacidade de captar as questões que mobilizam os grupos, os consensos e dissensos entre eles e o modo e eficácia de suas argumentações. Além disso, a participação nos grupos focais funciona também como um meio de os agentes sociais se conhecerem e se motivarem em torno da ideia do Conselho Consultivo e da solução conjunta dos problemas comuns a eles e ao PARNA da Tijuca. Segundo o IBASE (2005, p. 33) esta técnica "enfatiza a compreensão dos problemas do ponto de vista dos grupos e das instituições, além do conhecimento de suas aspirações, expressos por eles mesmos".

Moderadores plenamente capacitados conduziram os grupos focais, que por sua vez foram formados em torno de grandes temas. A mobilização para os grupos focais aconteceu em torno de maio de 2005 por meio de uma carta-convite aos representantes de várias organizações inventariadas na primeira etapa e listadas para participarem dos grupos focais. O s grupos de atores convidados estão listados a seguir (IBASE, 2006):

1 - concessionários e operadores de serviços privados atuando de forma permanente dentro do parque;

2 - órgãos públicos atuando permanentemente dentro do parque;

3 - unidades de Conservação no entorno do parque e comitês gestores de recursos hídricos que envolvessem as bacias hidrográficas nascentes dos maciços da Tijucae daCarioca;

4 - comunidades do entorno, incluindo associações de moradores de bairros e de favelas;

5 - instituições de ensino e pesquisa, com prioridade para as instituições de ensino e pesquisa que já tivessem realizado estudos sobre questões socioambientais do parque;

6 - grupos de visitação, de voluntariado e outros grupos de apoio ao parque (montanhistas, excursionistas, escoteiros etc.); $\mathrm{e}$

7 - funcionários da fiscalização e da segurança atuando dentro do parque.

Em função da grande quantidade de comunidades do entorno (cerca de quarenta e seis), foram convidadas apenas as associações de bairro e associações de moradores de favelas que exerciam forte pressão sobre o parque ou que tivessem histórico de parceria com o este. Uma identificados os problemas, conflitos e potencial de parcerias e atividades sustentáveis, foi concebido um plano de ação para mobilizar os agentes sociais estratégicos identificados na fase anterior. Com base neste plano, os grupos de atgentes sociais estratégicos foram convidados a participar de reuniões plenárias, divididas por setor do parque, onde foram apresentados os resultados do diagnóstico socioambiental e discutidos os critérios que orientariam a recomposição do Conselho Consultivo. E stas reuniões acontece- 
ram a partir de novembro de 2005. Aos presentes nessas reuniões foram distribuídos formulários de pré-candidatura ao Conselho Consultivo do parque. Vinte e seis instituições postularam sua pré-candidatura, sendo oito estatais e dezoito da sociedade civil. Houve ainda várias reuniões que se estenderam até meados de 2006 para se chegar a uma composição final do novo Conselho, com base no critério de paridade entre representantes estatais e da sociedade civil e que estipulou um total de vinte e quatro membros do Conselho.

Segundo a gestora do PARNA da Tijuca, em junho de 2006, aguardava-se a publicação de uma portaria do IBAMA permitindo capacitar os membros do Conselho, isto é, treinálos sobre questões ambientais, legais e sobre o PARNA daTijuca, a fim de que pudessem cumprir satisfatoriamente suas funções. Em 19 de dezembro de 2006, foi publicada a Portaria no 103, do IBAMA, que alterava a composição do Conselho Consultivo do parque. $O$ novo Conselho tomou posse em janeiro de 2007 com a responsabilidade inicial de aprovar seu regimento e elaborar planos de ação.

A recomposição do Conselho Consultivo do PARNA da Tijuca é, sem dúvida, exemplar quando se considera a diretriz de participação da sociedade na gestão do parque. A metodologia utilizada pelo IBASE leva em consideração os atores sociais do entorno e suas aspirações, bem como as necessidades de empresas e outras organizações. Ainda que o Conselho não venha a ter poder de deliberação, sua mera existência e atuação contínua ensejam melhorias para o PARNA da Tijuca e para as comunidades em seu entorno.

\section{CONCLUSÕESE RECOMENDAÇÕES}

O Q uadro 1 a seguir resume a análise dos dois casos quanto à gestão participativa via Conselhos Consultivos, os quais operacionalizam a estratégia colaborativa dos parques.
Cabemencionar que dos oito parques analisados na pesquisa maior apenas um (PNM Bosque da Freguesia) tinha seu Conselho Consultivo em pleno funcionamento durante a pesquisa, mas, ainda assim, de forma provisória, e até irregular. Entre os demais, quatro parques estavam formando seus conselhos e três ainda não haviam iniciado o processo. D os parques em implantação, sem dúvida nenhuma, o PARNA daTijuca foi aquele em estado mais adiantado, tanto que, após o encerramento da coleta de dados, o processo chegou ao final, tendo 0 Conselho sido empossado em 2007. 0 aspecto mais importante a ser mencionado porém, é quanto à metodologia utilizada para a formação dos conselhos. Aqui, o PARNA da Tijuca se destaca de forma exemplar, ao adotar, em parceria com a O NG Terra Azul, tendo o IBASE como consultor, uma metodologia absolutamente participativa, tomando todo o processo não apenas democrático, mas, acima de tudo, includente e motivante para os agentes sociais que dele participaram, eliminando as barreiras à colaboração, como preconizam Wondolleck eYaffee (2000). Já o PNM Bosque da Freguesia não possuía normas nem procedimentos para implantação de conselhos consultivos, carecendo de recursos humanos em quantidade adequada para dar suporte a tantos processos de formação de Conselhos, correndo, ao mesmo tempo, fato muito semelhante ao relatado em Horowitz e Bursztyn (2004). Além disso, a ideia do Conselho parece não ter sido ainda internalizada entre todos os gestores de parques, o que indica a necessidade de reciclagem deles sobre o tema.

É necessário também ressaltar aimportância da capacitação de todos os agentes sociais para conhecerem a lei do SNUC e entenderem seus deveres e direitos como membros do Conselho. Os gestores também deveriam passar por um treinamento específico que os ajudasse a liderar um Colegiado, tanto na fase de formação quanto na sua condução, e a estar aptos a lidar com

\begin{tabular}{|c|c|c|}
\hline Itens de Análise & $\begin{array}{l}\text { Parque Natural Municipal do Bosque da } \\
\text { Freguesia }\end{array}$ & Parque Nacional da Tijuca \\
\hline Status do Conselho Consultivo & $\begin{array}{l}\text { Em fundionamento provisório durante a pesquisa } \\
\text { e suspenso até hoje para redefinição das norm as }\end{array}$ & $\begin{array}{l}\text { Conselho recm posto e em possado logo } \\
\text { após o ter-mino da pesquisa. }\end{array}$ \\
\hline $\begin{array}{l}\text { N ormas e metodologia para } \\
\text { conselhos }\end{array}$ & Em elaboração & $\begin{array}{l}\text { E laboradas junto } 0 \mathrm{~m} \text { IBASE - } \\
\text { to talm ente participativas }\end{array}$ \\
\hline $\begin{array}{l}\text { Identific ação dos Atores } \\
\text { sociais do Conselho }\end{array}$ & Realiz ada por m eio de reuniões & $\begin{array}{l}\text { Realizada por diagnóstio so cioambiental } \\
\text { e grupos fo cais }\end{array}$ \\
\hline $\begin{array}{l}\text { Mobilização dos atores sociais } \\
\text { do Conselho gestor }\end{array}$ & Reuniões periódicas do Conselho e campanhas & $\begin{array}{l}\text { Reuniões plenánias e form ulário de pré- } \\
\text { candidatura ao Conselho }\end{array}$ \\
\hline $\begin{array}{l}\text { Postura do gestor em relação } \\
\text { ao Conselho }\end{array}$ & $\begin{array}{l}\text { Disaurso favorável e ação às vezes œntrária, por } \\
\text { falta de capacitação }\end{array}$ & $\begin{array}{l}\text { Discurso favorável e ação embasada em } \\
\text { m etodologia }\end{array}$ \\
\hline $\begin{array}{l}\text { Configuração resultante da } \\
\text { interação }\end{array}$ & $\begin{array}{l}\text { Colaboração no início e onflito ao final, fruto de } \\
\text { desgaste, falta de normas e de capacitação. } \\
\text { Gestora acabou sendo retirada do cargo. }\end{array}$ & $\begin{array}{l}\text { Colaboracão to tal e atores so diais } \\
\text { motivados }\end{array}$ \\
\hline
\end{tabular}

Q uadro 1: Análise dos Conselhos Consultivos por Parque

Fonte: Elaborado pelos autores

LCONTEXTUS Revista Contemporânea de Economia e Gestão. Vol.7 - № 1 - jan/ jun/ 2009. (81-92). 
os conflitos que inevitavelmente surgirão, como no caso do PNM Bosque da Freguesia. Habilidades de comunicação, condução de reuniões e negociação devem ser passadas a todos os gestores. Além disso, em razão do número de conselhos a serem formados em breve, é aconselhável que seja montada uma estrutura interna na Secretaria Municipal de Meio Ambiente (SMAC) apenas para ajudar os gestores nesse processo.

Com base no foi analisado em cada caso, pode-se concluir que:

1 - o Conselho Consultivo pode ser uma arena importante para discussão e mobilização dos atores sociais do entorno, como mostrou o caso do PARNA da Tijuca,corroborando Teixeira et al. (2004), mas também pode ser fonte de conflitos, se não houver plena capacitação de seus participantes, aí incluídos os gestores dos parques (como no caso do PNM Bosque da Freguesia), aspecto mencionado por O liva e Costa Neto (2000) e Horowitz e Bursztyn (2004);

2 - para garantir que o Conselho Consultivo dos parques seja instrumento efetivo de participação da sociedadee de ajuda à gestão dos parques, é necessário que as discussões realizadas dentro deles e as propostas ou demandas daí advindas sejam realmente levadas a sério pelos órgãos centrais de decisão mesmo que não possam ser sempre aceitas ou atendidas. Atualmente, a atitude da SMAC tem o efeito de uma barreira à colaboração, como alertam Wondoleck eYafee (2000);

3 - é necessário que haja normas e procedimentos bem claros para a implantação e funcionamento do Conselho e que a identificação e mobilização dos atores sociais sejam feitas com métodos adequados e participativos, como aconteceu no PARNA daTijuca. Parcerias com O NG s ambientais e sociais especializadas neste tipo de atividade podem ser boa alternativa à falta crônica de recursos nos órgãos centrais.

Quando se comparam as gestões dos parques no nível centralizado, conclui-se que a esfera municipal, representada pela Secretaria Municipal do Meio Ambiente (SMAC), está mais atrasada em termos de formação de conselhos consultivos. Já a esferafederal, representada pela Coordenadoria Regional do IBAMA, responsável pelo PARNA da Tijuca, é a que alcançou o maior grau de gestão participativa visando a atingir os cinco objetivos propostos pelo SNUC para os parques. 0 modelo implantado no PARNA da Tijuca parece ser aquele a ser seguido pelos demais governos / órgãos gestores em seus respectivos parques.

\section{REFERÊNCIAS}

ACSELRAD, Henri. As práticas espaciais e o campo dos conflitos ambientais. In: Acselrad, Henri. Conflitos Ambientais no Brasil. Rio de Janira Relume Dumará : Fundação Heinrich Boll, 2004

BRA SIL. Le no9.985, de18 deJulho de2000. Regulamenta 0 artigo 225, § 10, incisos I, II, III e VII da Constituição Federal, institui 0 Sistema Nacional de Unidades de Conservação da Natureza e dá outras providências. Ministério do Meio Ambiente, Brasilia. Disponível em <http:/ / www.mma.gov.br/ port/ sbf/ dap/ doc/ snuc.pdf> . Acesso em 15 de abril de 2006.
BRASIL. D ecreto Federal $n^{\circ}$ 4.340. Regulamenta artigos da lei № 9.985, de 18 de julho de 2002, que dispõe sobre o Sistema Nacional de Unidades de Conservação da Natureza - SNUC, e dá outras providências. Diánio đicial [da] União de 23/ 08/ 2002. Brasília - D F. BREDARIOL, Celso. II - Conflitos ambientais na cidade do Rio de Janeiro. In: SCOTTO, G., LIMO NCIC, F. (O rg.). Conflitos sóioambientais mo Brasil, v. II. Rio de Janeiro: IBASE, 1997.

Conflito ambiettal enegocarẫo para uma pdítica local demio andiente Tese (D outorado em Engenharia). Rio de Janeiro: UFRJ; COPPE, 2001.

BURT O N, John; D UK ES, Frank. Conflict: Practices in Management, Settlement and Resolution. In: Commmity Mediation New York: St. Martin's Press, 1990

CO STA, Heloisa S.M., BRAGA, Tânia M. Entre a conciliação e o conflito: dilemas para o planejamento e a gestão urbana e ambiental. In: Acselrad, Henri. Conflitos Ambientais no Brasil. Rio de Janeiro: Relume D umará : Fundação Heinrich Boll, 2004

CRESWELL, John W. Research D esign: Q ualitative, Q uantitative and Mixed Methods approaches. 2nd, edition. Sage Thousand Oaks: 2003

DE MIO, G. P. ;FERREIRA FILHO, E.;CAMPOS, J. R. . Abordagens alternativas na resolução de conflitos ambientais. In: Benjamin, A. H..(Org.). Fauna, Pdíticas Públicas eInstrumentos Legais 1 ed. São Paulo: Revista dos Tribunais, 2004, v. 1, p. 373-395

G O HN, Maria da G lória M. Consdhos gestores eparticiperãa sociopdítica Cortez, 2001.

GRAY, Barbara. Conditions fadilitating intercrganizational ollaboration Human Relations 38, 1985, p. 912

HEALEY, Patsy. CollaborativePlanning Shaping Places in Fragmented Societies. Palgrave: Macmillan. UK. 1997.

HO ROWITZ, C., BURSZTYN, M., A., A., Unidades de Conservação e o paradigma da sustentabilidade: $O$ exemplo do Parque Nacional de Brasília. IV Congesso Brasilero de Unicadks de Conservaçãa v. 1, 2004, p. 82-91.

OLIVA, A., MAGRO, T., C., A evolução do planejamento do entorno das unidades de conservação de proteção integral. IV Congresso Brasileiro de Unidades de Conservarãa, v. 1, 2004, p. 462-473.

OLIVEIRA, C., A., SANTO S, C., J., F., Florestas Urbanas: normas de uso e ocupação do solo para proteção de unidade de conservação nas cidades. IV Congresso Brasilerro de Unidades de Conservaçãa, v. 1, 2004, p. 542-549.

PCRJ-SMAC (Prefeitura do Rio de Janeiro/ Secretaria Municipal do Meio Ambiente). Guia das Unidades de Conservação Anbiental do Rio deJanira Rio de Janeiro: SMAC. 1998.

PCRJ - SMAC (Prefeitura do rio de Janeiro/ Secretaria Municipal do Meio Ambiente). Reatónio de Gestão da Sentaria Mumiapal de Meio Ambiente no períob 19942004 Rio de Janeiro: SMAC. 2004

REMENYI, D an, WILLIAMS, Brian et al. DaingReserch in Business andManagement: An introduction to process and method. Sage.1998 RÖPER, M., A difícil arte do planejamento participativo: a implementação da APA Estadual de Chapada dos G uimarães como exemplo de institucionalização territorial. Anais do II Congesso Bra silero de Unidades de Conservação v II, 2000, p. 69-78.

SACHS, Ignacy. Estratégas de transição para o séulo XXI, Deendvimento e Méo Anbiente São Paulo. Studio Nobel.1993.

SCANDURRA, Enzo. L'Ambienteddl'uana Verso il progetto della città sostenible. Milano: Etaslibri . 1a. Edição. 1995. 
SilVA, F., H., A., BONillA, O., H., OLIVEIRA, C., S., F. Efetividade das Unidades de Conservação de Proteção Integral na Manutenção da Biodiversidade do Ceará. IV Congresso Brasileiro de Unidades de Conservaçãa v. 1, 2004, p. 532-541.

SMAC. Site Oficial da Secrtaria Muniapal do Meio Ambiente do Rio de Janira D isponível em <http:/ / www.rio.rj.gov.br/ smac/ > . A cessado en $06 / 10 / 2006$

SO UZA, Ilma et al. DIPUC- Diagnóstico participativo de Unidades de Conservação. In: III Congresso Brasileiro deUnidades deConservação, 2002, Fortaleza. Anais. Fortaleza: Rede Nacional Pró Unidades de Conservação Ambiental, 2002, 1v., 876 p.3-12.

TEIXEIRA, K., A., PACHECO, M., A., DUTRA, R., M., A. Criação do Conselho Consultivo da Área de Proteção Ambiental - APA João Leite/ G oiás. Anais do IV Congresso Brasileiro de Unidades de Conservaçãa v. 1, 2004, p. 21-29.

TCMRJ - Tribunal de Contas do Município do Rio de Janeiro. Auditoria Operacional em Unidades de Conservaçãa Rio de Janeiro. 2005.

WO ND OLLECK, Julia, YAFFEE, Steven. Sustaining the Surcess of Cdlaborative Partnerships, research report submitted to the USDA-Forest Service Pacific Northwest Research Station, Seattle, July 15, 1997. . Making Collabaration Work: Lessons from Innovation in Natural Resource Management. Washington,D C. Island Press. 2000. YIN, Robert K. CaseStudy Researdh- Design and Methods Sage. 2nd. Edition. 1994, 